RIVERA ANDÍA Juan Javier, La vaquerita y su canto, una antropología de las emociones. Canciones rituales ganaderas en los Andes peruanos contemporáneos

\title{
Lucila Bugallo
}

\section{(2) OpenEdition \\ 1 Journals}

Edición electrónica

URL: https://journals.openedition.org/jsa/16625

DOI: 10.4000/jsa. 16625

ISSN: 1957-7842

Editor

Société des américanistes

\section{Edición impresa}

Fecha de publicación: 15 diciembre 2018

Paginación: 210-215

ISSN: 0037-9174

\section{Referencia electrónica}

Lucila Bugallo, "RIVERA ANDía Juan Javier, La vaquerita y su canto, una antropología de las emociones. Canciones rituales ganaderas en los Andes peruanos contemporáneos», Journal de la Société des américanistes [En línea], 104-2 | 2018, Publicado el 15 diciembre 2018, consultado el 03 septiembre 2022. URL: http://journals.openedition.org/jsa/16625 ; DOI: https://doi.org/10.4000/jsa. 16625

Este documento fue generado automáticamente el 3 septiembre 2022.

All rights reserved 


\title{
RIVERA ANDÍA Juan Javier, La vaquerita y su canto, una antropología de las emociones. Canciones rituales ganaderas en los Andes peruanos contemporáneos
}

\author{
Lucila Bugallo
}

\section{REFERENCIA}

RIVERA ANDÍA Juan Javier, La vaquerita y su canto, una antropología de las emociones. Canciones rituales ganaderas en los Andes peruanos contemporáneos, Rumbo Sur (Ethnographica), Buenos Aires, 2016, 192 p., biblogr., index, fotos en blanco y negro.

1 Abordar el ritual ganadero de la herranza de vacunos en una región de los Andes a partir de las canciones que en ese contexto suenan resulta de interés por varios motivos: se pone en evidencia desde un conocimiento etnográfico la importancia para los pueblos andinos de los diversos animales criados, tanto los autóctonos como las especies animales llegadas con los europeos, como en el caso de los vacunos. Pero interesarse en el ritual desde el canto nos lleva a considerar el universo de lo sensible, el importante lugar de los sentidos en la conformación de relaciones y significados, y desde allí nos permite adentrarnos en entramados emotivos. Porque las canciones que escuchó y en las que se interesó Juan Javier Rivera Andía en el valle de Chancay de la sierra limeña, llamadas taki y anti, refieren a las vacas y a los toros, pero también a la relación con las personas que los crían y a la vez deciden su sacrificio. En esas emociones cantadas, surgen experiencias y valores entorno al amor, las migraciones y el desarraigo, y junto con todo ello la añoranza de la juventud, del pago, del lugar del que somos; al dejarnos llevar a la comprensión de sentidos profundos y complejos, se termina por entender que somos ese 
lugar. Es importante indicar que Rivera Andía toma al rito y las canciones como comentarios sobre las cuestiones enunciadas; son el modo que tienen la comunidad campesina y los emigrados, que retornan en estas ocasiones, para expresar sus valores, perspectivas y sentimientos. El autor propone considerarlos comentarios críticos de problemáticas ideológicas actuales, es decir que forman parte de los nuevos modos de ser ganadero entre el campo y la ciudad.

tibro se compone de una introducción y de cinco capítulos, ubicados en dos secciones, y termina con una conclusión y un epílogo. La primera parte, "La herranza del ganado vacuno en el Valle de Chancay", consta de dos capítulos. En el primero se presenta el espacio de las alturas, para el que se brindan datos sobre las producciones mostrando la complementariedad entre ganadería y agricultura, y se centra la atención en el lugar que éste ocupa en el imaginario y las valoraciones locales. Las canciones incluyen toponimia local, en particular de los lugares del ganado, y nombran a sus principales habitantes: el awkillo, divinidad tutelar de los cerros (también conocido como auki, apu o achachila), concebido en tanto dueño del ganado, y principalmente a los llakwash o pastores de las alturas, que tienen asimismo la connotación de foráneo. Este espacio y sus espíritus tutelares son temidos y venerados al mismo tiempo. A la vez, la figura del pastor aparece con una serie de connotaciones contrastadas: es despreciado, es miserable, se encuentra aislado, es un ser errante que suscita compasión, pero al mismo tiempo sus sacrificios se muestran como un valor mientras que los patrones son considerados mezquinos. El pastor es comparado con los animales ariscos de las alturas, es un humano semianimalizado; las canciones refieren a la relación entre humanos y animales, asunto en el que se concentra el ritual. Se presenta en este capítulo la oposición entre pastores y agricultores, como una manera de oposición entre espacios diferenciados y a la vez complementarios desde la relación contractual que implican los intercambios. Aquí el autor propone una comparación con las características de los pastores europeos, en particular ibéricos, preguntándose por las atribuciones que éstos tienen y de qué manera se encontrarían en el imaginario del valle de Chancay. Si bien todo el desarrollo sobre la caracterización de llakwash y pastores es de gran interés, considero que esta comparación entre la sierra de Lima y los pastores europeos hubiese merecido mayor desarrollo y evidencia. En el segundo capítulo Rivera Andía desarrolla los sentidos de la herranza, análisis que supone buscar las significaciones sociales e identificar las categorías simbólicas y sensibilidades que las ordenan. En este ritual se expresan valores morales que atañen a la animalidad, a la adolescencia y al desarraigo. Los valores referidos a la juventud aparecen en analogías que se presentan entre los animales y las etapas del ciclo vital de los humanos, mostrando los procesos de domesticación animal y de maduración humana como análogos. Luego termina introduciendo la segunda parte del volumen: el desarraigo del lugar propio muestra el sacrificio de la gente que debe dejar a las familias y a los padres, olvidando lo propio para aprender lo novedoso de la vida moderna de las ciudades. Nuevamente aparece la analogía con los animales que son amados y sacrificados; el ganado es entrañable y a la vez una mercancía que se puede comprar y vender -práctica y valores que se asemejan a las experiencias urbanas de los campesinos emigrados. Las canciones dejan entrever la nostalgia por el lugar como la añoranza por un pasado, ligado tanto con ciertas etapas en el ciclo de la vida como con el origen de un linaje.

3 Compuesta de tres capítulos, la segunda parte, "Del sentimiento trágico de las canciones ganaderas", comienza buscando el modo de comprender el mundo emocional y se 
pregunta qué es lo que causa tanta emoción a las personas en este contexto ritual en el que se expresan de un modo que no ocurre en otros. El autor encuentra que las emociones se relacionan con los animales pero a la vez con la vida de los criadores, dado que las canciones enuncian la contradicción de dejar el propio lugar y de matar a los animales que se crían y aman. Para Rivera Andía estas canciones contienen una crítica a la modernidad actual, al mercantilismo y capitalismo en que se insertan los campesinos, a costa de dejar sus valores y prácticas, y hablan del modo en el que perciben los cambios y las transformaciones sociales. Esta parte continúa con un capítulo en el que se analiza concretamente un corpus de canciones buscando visibilizar qué es lo que conmueve a estas personas. Es ahí donde se anudan los sentidos: la emoción surge del amor, de la relación con los padres y animales siendo estos últimos tratados por momentos como progenitores; tal como expresa el autor, se trata de un "ritual que juega con la frontera entre hombres y animales" (p.93). En la herranza el ganado es incluido en un orden humano, con jerarquías y distinciones de género, es bautizado y se lo involucra en matrimonios; a su vez, las personas humanas toman comportamientos animales tanto sexuales como alimenticios. En las canciones se escucha la admiración y alabanza del ganado, al que se le reconoce su individualidad además de su identidad en el seno de un rebaño y familia; se resaltan sus cualidades y se le habla con cariño, es comparado con parientes entrañables de quienes suele tomar sus nombres. Se lo considera nutricio y fuente de riquezas como las minas: es como un banco en el que se guardan los ahorros. Algunas canciones son cantadas por los animales, a quienes los humanos prestan sus voces; en ellas el ganado se lamenta de su suerte y se queja a sus dueños implorando no ser entregado al matadero. El amor es también el de los amantes, y aquí vuelve la añoranza por la juventud; se extraña esa época de la vida como algo individual y se extraña otra época colectiva, en la que las familias estaban realmente allí. Los amores de juventud son comparados con los animales de las alturas: son salvajes, indómitos, intentan escapar a las normas. Pero finalmente los jóvenes maduran, se casan y se hacen cargo de sus compromisos sociales, los animales son llevados por un camino que los termina convirtiendo en mercancía. Es una de las contradicciones a las que aluden las canciones y de allí surgen la emoción, la pena y la añoranza.

El libro refiere a los migrantes campesinos que ahora están en las ciudades; de hecho gran parte de la organización del ritual y sus costos económicos recaen sobre ellos, que la mayoría de las veces son los dueños de los rebaños. El ritual ganadero se sustenta desde la economía citadina, y así se siguen tejiendo las historias de las familias y sus animales. Estas familias se dividen entre el campo y la ciudad y sus economías se construyen desde ambos espacios. Los momentos en que se encuentran son la ocasión para "comentar" sus historias a través de las canciones y el ritual. También son el modo de afirmar la pertenencia a la comunidad y el derecho a la tierra: "Las emociones asociadas a la emigración y a la modernización están retratadas en las canciones ganaderas" (p. 157). Se reúnen en estos cantos dos temas dispares que parecen provocar sentimientos análogos: el envío a la muerte del ganado que se ha criado con cariño, y la migración que implica el abandono del lugar propio obligando a cambiar de hábitos y generando "el dolor de ausencia" tal como expresa José Luis Grosso. Este autor propone que en la experiencia del destierro se construye el proceso de subjetivación social, apoyándose en rituales que posibilitan la pertenencia a la tierra. Los desarraigados buscan realizar un deseo imposible (Grosso 2008, p. 218-221). Pierre Bourdieu escribió asimismo sobre las contradicciones de la herencia: heredar el proyecto de progreso, corazón de la modernidad, suponía para las clases populares desheredar su propia cultura. Ser como los 
padres significaba fracasar en el proyecto de ascenso social (Bourdieu 1998, p. 443-448). En el trabajo de Rivera Andía se ven claramente estas contradicciones de las herencias: continuar siendo criador mientras se vive en la ciudad, sentir la pena del desarraigo del mismo modo que se siente la pena al ver partir hacia la matanza al ganado que se ha criado como familia. Posiblemente sea la añoranza de todas las sociedades que luchan por sus herencias buscando alguna manera de articularlas con los cambios del mundo global.

5 La segunda parte concluye con la hipótesis según la cual se dan dos ocultamientos: el amor extremo hacia el ganado es un modo de esconder su lugar como mercancía; la experiencia de partida de los animales oculta el conflicto del desarraigo de los humanos. Como bien muestra Rivera Andía, la experiencia de emigrar es buscada y deseada. Como los nombres dados a los animales, las canciones también dejan entrever la valoración de lo novedoso, la seducción de lo extraño, la predilección por lo exótico y diferente que "alude al cosmopolitismo andino y amerindio" (p. 105). En las transformaciones que se operan en estas sociedades la búsqueda de lo foráneo ocupa un lugar importante. Es el tema del epílogo en el que el autor propone una discusión de fondo, con preguntas fundamentales para entender las sociedades andinas: la relación con el otro y con la propia identidad se construye desde una apertura a lo nuevo, a lo distinto, y no desde ideales de pureza y exclusión cultural. En este sentido la idea de resistencia pierde fuerza, siendo el interés por la innovación y lo extraño el motor de la persistencia. Este interés por lo distinto introdujo al ganado vacuno en mitos y rituales andinos, y es desde la "tradición" de la herranza que se interpreta e incorporan las nuevas transformaciones, por las que los indígenas y mestizos campesinos se incluyen en la modernidad: "La res en el valle de Chancay es, en cierto modo, una otredad asimilada en el corazón de una cultura (por medio del ritual), que sirve para acercarse a nuevas otredades (aquellas que pertenecen a la ciudad y sus encantos)" (p. 170). Silvia Rivera Cusicanqui (2010) considera que estas poblaciones han participado y participan de una modernidad americana cuyo proceso de desarrollo fue terreno de resistencias y conflictos, en el que se imaginaron y desarrollaron estrategias, lenguajes y proyectos propios, que tomaron sentidos distintos de los hegemónicos. Estos pueblos de los Andes tienen una comprensión amplia de lo humano como de lo no-humano y se interesan genuinamente por lo diverso. Aquí no se trata de una enunciación políticamente correcta, sino de un valoración de la otredad cuyas especificidades remiten a las propias lógicas identitarias (p. 181).

6 En relación con el corpus de canciones analizado, para algunos temas hay muchos ejemplos y para otros muy pocos. Sin embargo, el material recopilado es valioso, así como la búsqueda de otros ejemplos de décadas anteriores. Resulta muy interesante la perspectiva de análisis según la cual a través de las canciones al ganado la gente comenta su propia vida, en la tensión de los cambios del mundo global contemporáneo. Me parece importante señalar una ausencia en la bibliografía empleada por el autor: el texto de Denise Arnold y Juan de Dios Yapita (1998) sobre los cantos a los animales en situaciones rituales, que a mi entender constituye un volumen de referencia ineludible para la temática. Si bien trata sobre poblaciones y cantos del sur andino, creemos que hubiese sido muy rico tenerlo en cuenta a modo de comparación.

7 Una última cuestión relativa a este volumen refiere a la colección de la que forma parte: Ethnographica. Se trata de un interesante proyecto que pone el foco en la producción de etnografías de pueblos indígenas americanos, interesándose en el método de una manera compleja ya que sobrepasa un abordaje que lo consideraría únicamente como un modo 
de construcción de fuentes y propone pensarlo como el germen de teorías y propuestas conceptuales. La colección se aventura fuera de los lugares seguros y busca difundir otros modos antropológicos, visibilizando la etnografía simétrica y las investigaciones colaborativas. Esta dirección constituye una búsqueda por superar las herencias coloniales en el marco de una ciencia moderna, como es la antropología, lo que le da un nuevo aire y le brinda posibilidades de regeneración. El trabajo de Rivera Andía encuentra así su lugar en esta colección ya que se trata de una etnografía realizada en pueblos de los Andes peruanos, pero además incursiona en dimensiones antropológicas poco exploradas como son las emociones, presentando una propuesta de análisis en la que sitúa a los rituales ganaderos en la tensión de los mundos contemporáneos y no como fenómenos dentro de una tradición estable. Si bien no se trata de una investigación en colaboración con la gente del lugar, el modo en que son consideradas y reflexionadas las emociones, tomando aspectos del ritual y los temas de las canciones como exégesis local, es una manera de escuchar y dar lugar en el escrito antropológico a los comentarios locales. Es escuchar más allá de las canciones, con empatía, siguiendo la pena de desprenderse del animal, de dejar el lugar propio, siguiendo el hilo entre el cerro y la ciudad. La empatía es un cimiento de este trabajo, y es un sentimiento que considero en la base de toda buena etnografía.

\section{BIBLIOGRAFÍA}

\section{ARNOLD Denise y Juan de Dios YAPITA}

1998 Rio de vellón, río de canto. Cantar a los animales, una poética andina de la creación, ILCA, Facultad de Humanidades y Ciencias de la Educación, Carrerra de Literatura, Universidad Mayor de San Andrés (Colección Academia, 8), La Paz.

\section{BOURDIEU Pierre}

1998 "Las contradicciones de la herencia", in Pierre Bourdieu (comp.), La miseria del Mundo, Fondo de Cultura Económica, Buenos Aires, p. 443-448.

GRosso José Luis

2008 Indios, muertos, negros invisibles. Hegemonía, identidad y añoranza, Encuentro/Facultad de Humanidades, Universidad Nacional de Catamarca, Córdoba.

RIVERA CUSICANQUI Silvia

2010 Ch'ixinakax utxiwa. Una reflexión sobre prácticas y discursos descolonizadores, Tinta Limón, Buenos Aires. 


\section{AUTORES}

\section{LUCILA BUGALLO}

Instituto Interdisciplinario Tilcara, Facultad de Filosofía y Letras, Universidad de Buenos Aires/ Unidad de Investigación en Historia Regional, Facultad de Humanidades y Ciencias Sociales, Universidad Nacional de Jujuy 